\title{
ANALISIS PENDAPATAN USAHA TANI JAGUNG PIPILAN DI KECAMATAN PAYAKUMBUH
}

\author{
Imelfina Musthafa ${ }^{1}$, Toni Malvin ${ }^{2}$ dan Mukhlis ${ }^{1}$ \\ ${ }^{1}$ Program Studi Agribisnis Pertanian, Politeknik Pertanian Negeri Payakumbuh \\ ${ }^{2}$ Program Studi Peternakan, Politeknik Pertanian Negeri Payakumbuh \\ Jl. Raya Negara Km. 7 Tanjung Pati, 26271, Payakumbuh \\ Korespondensi:musthafa_se@yahoo.com
}

$\begin{array}{ll}\text { Diterima } & : 02 \text { Februari } 2018 \\ \text { Disetujui } & : 26 \text { Februari } 2018 \\ \text { Diterbitkan } & : 15 \text { Juli } 2018\end{array}$

\begin{abstract}
ABSTRAK
Penelitian ini didasarkan pada peningkatan produksi jagung di Kecamatan Payakumbuh yang diperlukan untuk meningkatkan pendapatan petani jagung, kondisi ini sejalan dengan meningkatnya kebutuhan komoditas jagung khususnya untuk pakan ayam petelur. Meningkatnya kebutuhan jagung untuk ayam petelur disebabkan oleh meningkatnya populasi dalam usaha perunggasan, khususnya ternak ayam petelur di Kecamatan Payakumbuh yang begitu cepat. Penelitian ini bertujuan untuk menganalisis pendapatan usahatani jagung. Untuk menganalisis pendapatan usahatani jagung dilakukan dengan analisis menggunakan rumus pendapatan usahatani. Hasil penelitian menunjukkan bahwa: Total pendapatan petani jagung adalah Rp.28.984 - 18.294.429; dengan penghasilan rata-rata $\operatorname{Rp} 5.089 .795,35$.
\end{abstract}

Keywords: Analisis, Penghasilan, Petani, Jagung

\begin{abstract}
This research is based on the increasing the production of corn in Payakumbuh District is needed to increase the income of corn farmers, this condition is in line with the increasing need for corn commodity especially for laying chicken feed. Increased requirement of corn for laying chicken is caused by the increasing of investment in poultry business especially chicken livestock laying in Payakumbuh District so fast. This study aims: 1) to analyze the income of corn farming. To analyze the income of corn farming is done by farming analysis using farm income formula. The results showed that: Total income of corn farmers is IDR 28.984 - 18.294.429; with an average income of IDR 5.089.795,35.
\end{abstract}

Keywords: Analysis, Income, Farmer, Corn 


\section{I.UMIBUNG}

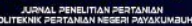

\section{PENDAHULUAN}

Pengembangan sektor pertanian ini dilakukan terutama melalui peningkatan subsektor pangan dan subsektor perkebunan. Salah satu komoditi tanaman pangan yang berperan dalam pembangunan sektor pertanian adalah jagung. Di Indonesia jagung merupakan komoditi pangan kedua setelah padi dan sumber kalori atau makanan pengganti beras, disamping itu, juga sebagai pakan ternak. Kebutuhan jagung terus meningkat dari tahun ke tahun sejalan dengan peningkatan taraf hidup ekonomi masyarakat dan kemajuan industri pakan ternak sehingga perlu upaya peningkatan produksi melalui sumber daya manusia dan sumber daya alam, ketersediaan lahan maupun potensi hasil dan teknologi. (Purwono dan Hartono, 2007).

Peningkatan produksi jagung di Kecamatan Payakumbuh sangat diperlukan guna untuk meningkatkan pendapatan petani jagung, kondisi ini seiring dengan semakin meningkatnya kebutuhan akan komoditi jagung terutama untuk pakan ayam ras petelur. Peningkatan kebutuhan jagung bagi ayam ras petelur disebabkan karena adanya peningkatan investasi pada usaha ternak unggas khususnya ternak ayam ras petelur di Kecamatan Payakumbuh yang begitu cepat. Adanya peningkatan investasi pada usaha ternak unggas akan berdampak kepada meningkatnya kebutuhan jagung pada usaha ternak unggas, sehingga akan meningkatkan pula pendapatan petani jagung.

Berdasarkan latar belakang dan permasalahan di atas dapat dirumuskan permasalahan dalam penelitian ini yaitu seberapa besar pendapatan usahatani jagung pipilan. Adapun tujuan dari penelitian ini adalah untuk menganalisa pendapatan usahatani jagung pipilan.

\section{METODE PENELITIAN}

Penelitian dilakukan di Kecamatan Payakumbuh. Penelitian ini dilakukan selama lebih kurang 8 bulan, mulai bulan April 2017 sampai bulan November 2017. Pemilihan daerah penelitian dilakukan dengan cara purposive methode atau sengaja (Sugiyono, 2013). Terpilih empat nagari yaitu Nagari Koto Baru Simalanggang, Nagari Koto Tangah Simalanggang, Nagari Simalanggang dan Nagari Taeh Baruah dengan dasar pertimbangan: 


\section{I.UMIBUNG}

1. Nagari terpilih merupakan sentra produksi jagung di Kecamatan Payakumbuh.

2. Nagari terpilih belum pernah diadakan penelitian tentang pendapatan usaha tani jagung.

Untuk menjawab tujuan penelitian diperlukan sampling. Menurut Singarimbun (2011), terdapat empat faktor yang harus dipertimbangkan dalam menentukan sampel dalam suatu penelitian yaitu :

1. Derajat keseragaman dari populasi, semakin seragam populasi itu, semakin kecil sampel yang dapat diambil.

2. Presisi yang dikehendaki dari penelitian, dimana makin tinggi tingkat presisi yang dikehendaki, makin besar sampel yang harus diambil.

3. Rencana analisa, dimana besar kecilnya jumlah sampel disesuaikan dengan rencana analisa yang dipakai, semakin rumit perhitungan statistik yang dipakai dan atau semakin banyak strata yang ditetapkan, biasanya semakin banyak sampel yang diperlukan.

Pengambilan sampel (Sampling Methode) untuk menjawab tujuan ini menggunakan metode pengambilan sampel bola salju (Snowball Sampling Methode). Menurut Rianse dan Abdi (2010), metode sampling bola salju digunakan apabila tidak tersedianya data jumlah populasi sehingga tidak dimungkinkan untuk membuat kerangka sampel. Dengan metode ini, mula-mula peneliti mencari responden yang sesuai dengan kriteria yang ditetapkan, kemudian dari responden ini akan menunjuk atau mengajak temannya yang lain untuk dijadikan sampel, dan seterusnya sampai jumlah sampel yang dianggap peneliti sudah mewakili secara representatif untuk menjawab tujuan penelitian. Adapun total jumlah sampel penelitian adalah 80 petani jagung pipilan.

Data yang dikumpulkan dalam penelitian ini adalah:

a. Data primer diperoleh dari petani responden atau petani sampel dengan melalui metode wawancara berdasarkan daftar pertanyaan/kuisioner yang telah disiapkan terlebih dahulu.

b. Data sekunder diperoleh dari berbagai instansi yang ada kaitannya dengan penelitian ini, disamping itu juga informasi dari berbagai pihak. 


\section{I.UMIBUNG}

Untuk menganalisa pendapatan usaha tani jagung pipilan, dilakukan analisa usaha tani menggunakan rumus pendapatan usaha tani (Suratiyah, 2008). Secara matematis dapat ditulis sebagai berikut:

$$
\begin{aligned}
& \text { Pd }=\mathrm{TR}-\mathrm{TC} \\
& \text { Dimana: } \mathrm{Pd}=\text { Pendapatan Usaha Tani } \\
& \mathrm{TR}=\text { Total Penerimaan } \\
& \mathrm{TC}=\text { Total Biaya } .
\end{aligned}
$$

\section{HASIL DAN PEMBAHASAN}

\section{Jumlah Pendapatan Usaha Tani Jagung Pipilan}

Berdasarkan data primer yang diperoleh dari hasil survei, tabulasi dan pengolahan data, maka dapat diperoleh jumlah pendapatan petani jagung pipilan yakni Rp 28.984 - Rp 18.294.429. Pendapatan rata-rata yang diperoleh petani sebesar Rp 5.089.795,35. Untuk lebih jelas dapat dilihat pada Tabel 1.

Tabel 1. Jumlah pendapatan petani jagung pipilan di Kecamatan Payakumbuh

\begin{tabular}{lrrrrr}
\hline No & Pendapatan & No & Pendapatan & No & Pendapatan \\
\hline 1 & 18.294 .429 & 28 & 472.464 & 55 & 14.677 .637 \\
2 & 15.224 .577 & 29 & 14.459 .651 & 56 & 7.489 .644 \\
3 & 4.618 .357 & 30 & 1.804 .843 & 57 & 8.029 .644 \\
4 & 4.057 .261 & 31 & 4.491 .853 & 58 & 2.568 .882 \\
5 & 9.222 .228 & 32 & 718.656 & 59 & 7.479 .642 \\
6 & 3.292 .295 & 33 & 3.857 .329 & 60 & 1.614 .911 \\
7 & 3.844 .823 & 34 & 3.759 .850 & 61 & 3.089 .821 \\
8 & 7.134 .769 & 35 & 1.392 .348 & 62 & 3.359 .824 \\
9 & 1.296 .442 & 36 & 1.074 .917 & 63 & 9.049 .642 \\
10 & 2.312 .406 & 37 & 28.984 & 64 & 2.599 .874
\end{tabular}




\section{I.UMIBUNC}

\begin{tabular}{|c|c|c|c|c|c|}
\hline No & Pendapatan & No & Pendapatan & No & Pendapatan \\
\hline 11 & 5.712 .295 & 38 & 1.899 .897 & 65 & 9.579 .604 \\
\hline 12 & 11.557 .083 & 39 & 1.143 .658 & 66 & 2.409 .824 \\
\hline 13 & 6.749 .715 & 40 & 846.428 & 67 & 7.379 .630 \\
\hline 14 & 16.434 .419 & 41 & 8.457 .208 & 68 & 9.094 .519 \\
\hline 15 & 4.337.359 & 42 & 17.534 .435 & 69 & 2.814 .896 \\
\hline 16 & 8.604 .675 & 43 & 3.851 .376 & 70 & 2.554 .883 \\
\hline 17 & 10.609 .512 & 44 & 3.506 .853 & 71 & 1.514 .402 \\
\hline 18 & 2.156 .882 & 45 & 1.444 .391 & 72 & 2.264 .883 \\
\hline 19 & 1.711 .765 & 46 & 5.539 .769 & 73 & 1.344 .900 \\
\hline 20 & 4.172 .297 & 47 & 393.198 & 74 & 1.028 .407 \\
\hline 21 & 809.394 & 48 & 9.694 .529 & 75 & 3.829 .815 \\
\hline 22 & 5.677 .349 & 49 & 2.183 .352 & 76 & 1.279 .915 \\
\hline 23 & 3.084 .863 & 50 & 84.736 & 77 & 1.283 .903 \\
\hline 24 & 14.169 .563 & 51 & 509.891 & 78 & 5.409 .885 \\
\hline 25 & 10.537 .095 & 52 & 10.479 .630 & 79 & 3.129 .828 \\
\hline 26 & 8.262 .244 & 53 & 3.775 .822 & 80 & 1.914 .908 \\
\hline 27 & 839.915 & 54 & 2.259 .825 & $\overline{\mathbf{y}}$ & 5.089.795,35 \\
\hline
\end{tabular}




\section{KESIMPULAN}

Berdasarkan hasil penelitian yang telah dilakukan dan sesuai dengan tujuan dari penelitian, maka dapat ditarik kesimpulan, yaitu: Jumlah pendapatan petani jagung pipilan adalah Rp 28.984 - Rp 18.294.429; dengan pendapatan rata-rata petani sebesar Rp 5.089.795,35.

\section{REFERENSI}

Adisarwanto, T., Widyastuti dan Y. Erna. 2008. Meningkatkan Produksi Jagung di Lahan Kering, Sawah dan Pasang Surut. Penebar Swadaya. Jakarta.

[DISPANGHORBUN] Dinas Tanaman Pangan dan Hortikultura Kabupaten Lima Puluh Kota, 2011. Statistik Tanaman Pangan, Hortikultura dan Perkebunan Tahun 2011. Payakumbuh.

2012. Statistik Tanaman Pangan, Hortikultura dan Perkebunan Tahun 2012. Payakumbuh.

2013. Statistik Tanaman Pangan, Hortikultura dan Perkebunan Tahun 2013. Payakumbuh.

2014. Statistik Tanaman Pangan, Hortikultura dan Perkebunan Tahun 2014. Payakumbuh.

2015. Statistik Tanaman Pangan, Hortikultura dan Perkebunan Tahun 2015. Payakumbuh.

2016. Statistik Tanaman Pangan, Hortikultura dan Perkebunan Tahun 2016. Payakumbuh.

Purwanto, Siwi. 2008. Perkembangan Produksi dan Kebijakan dalam Peningkatan Produksi Jagung. Direktorat Budi Daya Serealia, Direktorat Jenderal Tanaman Pangan. Jakarta.

Purwono dan Hartono, Rudi. 2007. Bertanam Jagung Unggul. Penebar Swadaya. Jakarta.

Rahim, Abd. dan Hastuti, Diah Retno Dwi. 2008. Pengantar, Teori dan Kasus Ekonomika Pertanian. Penebar Swadaya. Jakarta.

Rukmana, Rahmat. 1997. Usahatani Jagung. Penerbit Kanisius. Yogyakarta.

Rianse, Usman dan Abdi. 2010. Metodologi Penelitian Sosial dan Ekonomi-Teori dan Aplikasi. Penerbit Alfabeta. Bandung. 


\section{I.UMIBUNG}

Sarasutha, I.G.P. 2002. Kinerja Usaha Tani dan Pemasaran Jagung di Sentra Produksi. Jurnal Penelitian dan Pengembangan Pertanian. Balai Penelitian Tanaman Serealia. Sulawesi Selatan.

Singarimbun M, 2011. Metode Penelitian Survei. Lembaga Penelitian. Pendidikan dan Penerangan Ekonomi dan Sosial. Jakarta.

Sugiyono. 2013. Metode Penelitian Kuantitatif dan Kualitatif dan R \& D. Alfabeta. Bandung.

Suratiyah, Ken. 2008. Ilmu Usahatani. Penebar swadaya. Jakarta.

Wirartha, I Made. 2006. Metode Penelitian Sosial Ekonomi. Penerbit CV Andi Offset. Yogyakarta 